This PDF is a selection from a published volume from the National Bureau of Economic Research

Volume Title: Targeting Investments in Children: Fighting Poverty When Resources are Limited

Volume Author/Editor: Phillip B. Levine and David J. Zimmerman, editors

Volume Publisher: University of Chicago Press

Volume ISBN: 0-226-47581-6

ISBN13: 978-0-226-47581-3

Volume URL: http://www.nber.org/books/levi09-1

Conference Date: September 26, 2008

Publication Date: August 2010

Chapter Title: Teen Pregnancy Prevention

Chapter Authors: Melissa Schettini Kearney

Chapter URL: http://www.nber.org/chapters/c11728

Chapter pages in book: (221 - 247) 


\title{
Teen Pregnancy Prevention
}

\author{
Melissa Schettini Kearney
}

\subsection{Introduction}

Teen childbearing is widely considered to be a major social problem in the United States. There are currently more than 400,000 teen births per year. Births to teen mothers account for roughly one-quarter of the nearly 1.5 million births per to unmarried women in the United States each year. ${ }^{1}$ Women who give birth during their teenage years experience negative economic and social outcomes, both in the immediate years and during early adulthood. They are more likely than other women to drop out of high school, to remain unmarried, and to live in poverty. The children of teenage mothers fare worse than other children on economic, social, and cognitive dimensions. ${ }^{2}$

In the year 2004, roughly seventy-two of every 1,000 girls age fifteen to nineteen in the United States became pregnant, and forty-one out of 1,000 gave birth. Cumulatively, nearly 30 percent of females become pregnant before age twenty and more than 20 percent give birth before age twenty. There is large variation in rates of teen pregnancy and childbearing across racial and ethnic groups, as shown in table 8.1. In 2004, the pregnancy rate among black and Hispanic teens was more than twice as high as among white teens. The birth rate among Hispanic teens was 82.6 per 1,000 , compared to 63.1 among black teens and 26.7 among white teens. ${ }^{3}$

The good news is that in 2004, the U.S. teen pregnancy rate was at its lowest level in thirty years, 38 percent lower than its peak in 1990. The

Melissa Schettini Kearney is an assistant professor of economics at the University of Maryland and a research associate of the National Bureau of Economic Research.

1. U.S. Department of Health and Human Services (2005, Table 18).

2. The award-winning book Kids Having Kids, edited by Rebecca Maynard (2007), is a widelycited consideration of the issue. An updated version is forthcoming from the Urban Institute.

3. Guttmacher Institute (2006). 
Table 8.1

Teen pregnancy and birth rates in the United States

\begin{tabular}{llll}
\hline & 1990 & 1995 & 2002 \\
\hline All teens & & & \\
$\quad$ Pregnancy rate & 116.9 & 99.0 & 75.4 \\
$\quad$ Birth rate & 60.3 & 56.0 & 43.0 \\
$\quad$ White teens & & & \\
$\quad$ Pregnancy rate & 98.8 & 84.9 & 65.0 \\
$\quad$ Birth rate & 51.2 & 49.5 & 39.4 \\
$\quad$ Black teens & & & \\
$\quad$ Pregnancy rate & 222.3 & 181.4 & 134.2 \\
$\quad$ Birth rate & 112.9 & 94.4 & 66.6 \\
$\quad$ Hispanic teens & & & \\
$\quad$ Pregnancy rate & 162.2 & 158.5 & 131.5 \\
$\quad$ Birth rate & 99.5 & 99.3 & 83.4 \\
\hline
\end{tabular}

Source: Guttmacher Institute (2006).

decline appears to reflect both a decrease in sexual activity and an increase in contraception (Santelli et al. 2004). Between 1988 and 2000, teen pregnancy declined in every state and the District of Columbia. But there is bad news as well. First, rates of teen pregnancy and childbearing in the United States remain substantially higher than in other industrialized nations. ${ }^{4}$ Second, the rate of decline was only half as large for Hispanic teens as for white and black teens. ${ }^{5}$ And third, teen birth rates increased between 2005 and 2006, the first year-to-year increase since 1991. Perhaps these facts should be taken as a challenge, in that they reveal there is still much room for improvement.

The past two decades have seen numerous and varied efforts from a wide set of actors - community groups, schools, nonprofits, and all levels of government - to bring down rates of teen pregnancy and childbearing in this country. Youth advocates, social scientists, and policymakers are all keenly interested in determining what caused the rise in teen childbearing in the 1980s and the subsequent decline in the 1990s. Unfortunately the research and policy community is far from being able to offer a conclusive answer to the question of what drove the rise and subsequent decline. If we could pinpoint the causes, we could confidently say what we need to continue doing in the years ahead. Unfortunately, the best we can do with any real

4. Because so many factors differ across countries-including economic institutions; inequality levels; cultural practices and norms; welfare, abortion, and contraception policies; as well as family and living arrangements - it is not well understood among researchers which factors in particular drive cross-country differences in teen pregnancy, abortion, and birth rates. In general, the particularly high rate among U.S. teens remains even if one considers only nonminority teens.

5. Guttmacher Institute (2006). 
confidence is to review what careful research reveals about the effectiveness of particular interventions in reducing rates of unprotected sex and teen pregnancy among targeted youth. This chapter focuses on program interventions, but it also includes a brief discussion of the potential impacts of relevant public policies.

The effectiveness of teen pregnancy prevention as an antipoverty strategy depends on two key elements: (a) the effectiveness of teen pregnancy prevention interventions in preventing teen pregnancies and births, and (b) the effectiveness of reducing teen childbearing in driving down rates of poverty. The bottom line of this review is that there is a lack of evidence demonstrating the effectiveness of many program interventions, but there is some cause for optimism that the best programs may work in the right settings. The most rigorous study of representative abstinence education programs fail to provide evidence that these programs are effective at reducing rates of sexual behavior. There are a few studies finding that select contraceptive-focused sexual education programs are potentially effective at reducing risky sexual behavior for targeted youth. The evidence regarding the effectiveness of multicomponent, expensive interventions (such as the Carrera program in New York City) is the most encouraging, but these programs can be quite expensive and difficult to replicate.

The latter part of the chapter reviews the evidence on the link between teen childbearing and subsequent economic outcomes, including rates of poverty, among teen mothers. On this second link, the evidence is weak that driving down rates of teen childbearing per se will lead to measurable reductions in poverty.

\subsection{Factors Driving Teen Pregnancy}

There is a vast literature exploring the antecedents and determinants of teenage pregnancy and childbearing. Study approaches and perspectives vary widely across academic disciplines. Noneconomists typically attribute early childbearing to be the result of myriad influences that affect a youth's development and fall outside the control of a rational decision-making process. Brooks-Gunn and Furstenberg (1989) identify five perspectives on adolescent sexual behavior: biological perspectives, parental influences, peer influences, academic perspectives, and social cognitive perspectives. BrooksGunn and Paikoff (1997) add to this list the importance of adolescent feelings in driving their behaviors. They propose four key topics that need to be explored in order to understand adolescent sexuality: sexual well-being and developmental transitions, the gendered nature of sexuality, decision making and sexuality, and the meaning of sexuality to youth. Many of the program interventions designed to educate teenagers about reproductive health and to reduce sexual activity and pregnancy risk have been developed with these broad theoretical perspectives in mind. 
Economists tend to model teen childbearing using a rational choice framework, positing that teens make decisions regarding sexual activity use and contraception in a cost-benefits framework. Cultural and peer influences are understood to affect that decision-making process, but they are not modeled explicitly. Public policies that alter the cost-benefit calculation are prime candidates for interventions affecting rates of teen childbearing. These include, but are not limited to, policies making welfare more or less attractive, policies making abortion more or less readily available, and policies increasing access to low-cost contraception. ${ }^{6}$

\subsection{Teen Pregnancy Prevention Programs}

\subsubsection{Overview}

Teen pregnancy prevention programs can be usefully categorized into three types: (a) sex education programs with an abstinence focus; (b) sex education with a contraception focus; and (c) multicomponent youth development programs that include sex education as one of many features. Some programs are based in schools and are compulsory, others are school-based but voluntary, and others are run through community centers and groups. There is substantial variation across programs in terms of the types of populations served, including racial and ethnic differences as well as age makeup of the teenagers involved.

There is disagreement among those who work in this field about whether sex education should be abstinence-focused. As helpfully explained by Scher, Maynard, and Stagner (2006), nearly all sex education programs explicitly mention that abstinence is the safest method for avoiding unwanted pregnancies and sexually transmitted infections (STIs). However, the difference between programs with an abstinence focus and a contraception focus is that programs of the latter type explicitly encourage the use of contraception among those who choose to become or remain sexually active. But there is large variation across these programs in the extent of their contraception component.

There have been a number of reviews of teenage pregnancy prevention programs. Scher, Maynard, and Stagner (2006) list twenty large-scale reviews published between 1994 and 2002. These reviews differ across one another in the methodological standards imposed on reviewed studies. They therefore include different studies in their reviews and meta-analyses (where applied) and often reach different conclusions about the effectiveness of

6. Moffitt (1998) provides a review of the evidence on the link between welfare and nonmarital childbearing; Grogger and Karoly (2005) provide a comprehensive review of the economic research on the impacts of welfare reform, including on nonmarital and teen childbearing; and Levine (2004) reviews the economic evidence on the link between abortion policy and fertility outcomes. 
particular types of interventions. Scher, Maynard, and Stagner (2006) only consider evaluations based on randomized control trials, yielding a sample of thirty-one evaluations conducted between 1981 and 2006. They further limit their sample to evaluations of programs with a primary goal of reducing heterosexual risk-taking behavior and that include measures of sexual experience, pregnancy risk, and/or pregnancy as outcomes. Note that many program evaluations have only short-term follow-up periods and focus on measures of attitude and knowledge, as opposed to actual risk-taking behavior.

Around the same time as the Scher, Maynard, and Stagner review, the National Campaign to Prevent Teen Pregnancy released Emerging Answers 2007, completed by Douglas Kirby. This report is a follow-up project to the widely-cited and popular 2001 publication by the same name. Emerging Answers 2007 reviews the evaluations of more than 115 teen pregnancy prevention programs in the United States published between 1990 and 2007. Kirby includes both random control trials and evaluations with quasiexperimental designs.

\subsubsection{Sex Education Programs with an Abstinence Focus}

The review by Scher, Maynard, and Stagner (2006) identifies only three abstinence-focused programs with evaluations that meet their criteria. These include the review of Education Now and Babies Later (ENABL) by Kirby et al. (1995); the review of Project Taking Charge by Jorgensen, Potts, and Camp (1993); and the review of McMaster Teen Program by Thomas et al. (1992). Their overall assessment of these reviews is that they provide no evidence that these particular programs changed the likelihood of sexual initiation or unprotected sex. But, the reviewers note that these somewhat outdated programs are not representative of the newer abstinence programs widely implemented today. Kirby's review of abstinence-focused programs also concludes that there is no convincing evidence that abstinence programs have the intended effect.

In April 2007, Mathematica Policy Research (MPR) issued a highly anticipated experimental design evaluation of four Title V, Section 510 Abstinence Education Programs. Section 510 of the 1996 Personal Responsibility and Work Opportunity Act (PRWORA) (welfare reform) legislation significantly increased funding for abstinence education. Since fiscal year (FY) 1998, the Title V, Section 10 program has allocated $\$ 50$ million annually in federal funding for programs that teach abstinence from sexual activity outside of marriage as the expected standard for school-age children. Under the matching block grant program administered by the Department of Health and Human Services, states must match this federal funding at 75 percent, resulting in annual expenditures of $\$ 87.5$ million for these programs. With the Balanced Budget Amendment of 1997 Congress authorized an evaluation of these programs, resulting in the Mathematica report. 
The Mathematica evaluation is a multiyear impact study of four programs: My Choice, My Future in Powhatan, Virginia; ReCapturing the Vision in Miami, Florida; Families United to Prevent Teen Pregnancy (FUPTP) in Milwaukee, Wisconsin; and Teens in Control in Clarksdale, Mississippi. The Miami and Milwaukee programs served a mix of urban communities and the Virginia and Mississippi programs served rural areas. The demographic make-up of the populations served by the four programs also varied, ranging from poor, single-parent minority families to middle-class, two-parent white households.

The four evaluated programs offered a range of implementation settings. All four programs were implemented in school settings, but the FUPTP program was an after-school program. Two of the programs (ReCapturing the Vision and FUPTP) were elective classes in school and the other two were nonelective. Three of the programs had mandatory attendance. None of the programs served high school students; two were in middle schools and two were in upper elementary grades. All programs offered more than fifty contact hours, making them among the more intense of Title V, Section 510 programs. ReCapturing the Vision and FUPTP were particularly intensive, meeting every day of the school year. Table 8.2 reports details of the programs and analysis samples.

The Mathematica evaluation was carried out with a "gold standard" randomized trial design. The final report presents estimated program impacts on youth behavior from a follow-up survey administered to 2,057 adolescents. By the time of the follow-up survey, youth in the study sample had all completed their programs. Though there are some positive differences in reported rates of knowledge about sexually transmitted disease (STD) identification and risks, there are no measured differences in key behavioral outcomes. About half of both program and control groups report remaining abstinent. When asked about the prior twelve months, 23 percent of both groups report having sex and always using a condom; 17 percent of both groups report having sex and only sometimes using a condom; and 4 percent of both groups report having had sex and never using a condom. Program and control groups also did not differ in the number of partners with whom they had sex. About one-quarter of all youth in both groups had sex with three or more partners. The findings of the Mathematica (2007) evaluation are quite sobering. The authors state in stark terms the challenge facing those who would design and implement teen pregnancy prevention programs: "The evaluation highlights the challenges faced by programs aiming to reduce adolescent sexual activity and its consequences. Nationally, rates of teen sexual activity have declined over the past 15 years, yet even so, about half of all high school youth report having had sex, and more than one in five report having had four or more partners by the time they graduate from high school" (xxiii). 


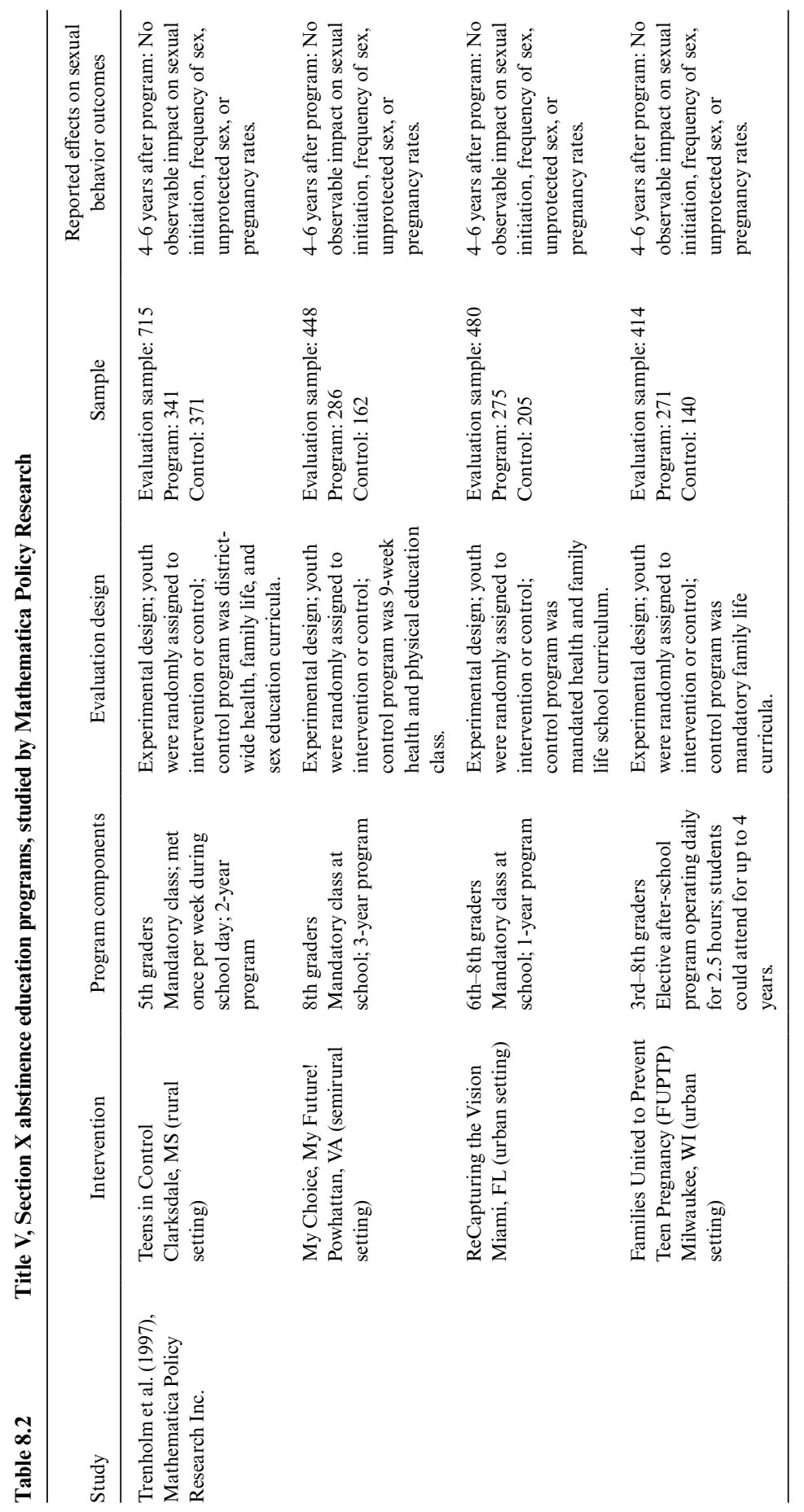




\subsubsection{Sex Education Programs with a Contraception Focus}

The evidence on the effectiveness of sex education programs with a contraception focus is somewhat more encouraging, though still limited. Kirby (2007) reviews forty-eight studies of comprehensive sex and STD/HIV education programs. Kirby reports that about two-thirds of the evaluations show a reduction in unprotected sex among program participants, but the large number of studies included means that there is variation in the rigor across the full set of studies. Scher, Maynard, and Stagner (2006) identify eighteen studies of programs of this type that meet their inclusion criteria, including four from 1990 or earlier and some with sample sizes of fewer than 100 observations. They conclude from these reviews that "there is no consistent evidence that sex education programs altered the likelihood that youth would initiate sex, would have unprotected sex, or would become (or get someone) pregnant" (37). However, they report that a number of individual studies found positive program effects, particularly related to increased contraception use. ${ }^{7}$ These include the evaluations by DiClemente, Wingood, and Harrington (2004) of an untitled HIV prevention serving African American females between ages fourteen and eighteen and the evaluation by St. Lawrence et al. (1995) of Becoming a Responsible Teen (BART). These programs are both summarized in table 8.3.

An important issue in determining the effectiveness of programs is whether positive results found for one implementation can be replicated in other communities, a point made by Kirby (2001). The program Be Proud! Be Responsible! and curricula derived from it have been evaluated a number of times. This program was designed to be implemented outside school, often on Saturdays. Original evaluations of three- and six-month implementations suggested positive results (Jemmott, Jemmott, and Fong 1992; and Jemmott, Jemmott, Fong, and McCaffree 1999). The program was modified, lengthened, implemented under the name Making Proud Choices! A Safer Sex Curriculum. A related abstinence curriculum was developed and named Making a Difference! A Sexual Abstinence Curriculum. Jemmott, Jemmott, and Fong (1998) evaluated the implementation of these programs in three middle schools in Philadelphia in the early 1990s.

The programs were run over the course of two Saturdays. Recruited participants - sixth- and seventh-grade boys and girls - were randomly assigned to one of three intervention groups: the safer sex intervention that included lesson modules about condom use and negotiation; the abstinence intervention; and a control intervention that consisted of a health promotion

7. Only five of these evaluations even measure pregnancy as an outcome and none of these are able to detect statistically significant effects. This could reflect either a lack of a true effect or merely statistical limitations. The number of pregnancies that are observed in any given year among a sample of a few hundred teens is quite small, making it difficult for evaluations of this kind to detect statistically meaningful changes. 
workshop. There were initially 659 sample adolescents; at the twelve-month follow-up there were 610 adolescents. At the twelve-month follow-up, for the full sample of youth, there were no statistically significant differences between participants in either treatment program relative to the control program in the likelihood of sexual intercourse or in the percent reporting unprotected sex. However, among the 102 adolescents who were sexually experienced at baseline, those in the safer sex program reported a lower frequency of unprotected sex as compared to control program participants and abstinence program participants.

This curriculum was adapted for Latino adolescents and named Cuidate! (translation: Take care of yourself!). A randomized implementation of this program from April 2000 through March 2003 was evaluated by Villarruel, Jemmott, and Jemmott (2006). Latino adolescents ages thirteen to eighteen were recruited from three northeast Philadelphia high schools and community-based organizations within these neighborhoods. The adapted program incorporated "salient aspects of Latino culture, specifically familialism, or the importance of family, and gender-role expectations. Abstinence and condom use were presented as culturally accepted and effective ways to prevent sexually transmitted diseases" (Villarruel, Jemmott, and Jemmott 2006, 773). The analysis found that adolescents in the program intervention were less likely to report sexual intercourse (odds ratio of 0.66 ) and more likely to report consistent condom use (odds ratio of 1.91). The positive results were driven by Spanish speakers. ${ }^{8}$

The program Becoming a Responsible Teen was evaluated in randomized trials in three settings. As described by Kirby (1997), first it was implemented in a community setting in urban Jackson, Mississippi. The program consisted of eight 90- to 120-minute meetings. The evaluation of this program by St. Lawrence et al. (1995) found that at a fourteen-month follow-up, program participants had delayed sexual initiation, reduced frequency of sex among sexually active youth, increased condom use, and reduced rates of unprotected sex. Second, the program was implemented in two drug rehabilitation centers in Mississippi. St. Lawrence et al. (2002) report that at a thirteen-month follow-up, program participants had increased abstinence, reduced number of sexual partners, increased condom use, and decreased rates of unprotected sex. But the total sample size for the evaluation sample was 142 , which raises questions about the power of the analysis to find statistically significant differences. And third, the program was shortened by more

8. A look at the evaluation data reveals that, in fact, the proportion of treatment respondents who reported consistent condom use actually decreased and the proportion of treatment respondents who reported sexual intercourse in the past three months increased, as compared to baseline reports; the evaluators' finding of program success is because these rates of decrease and increase are lower than the corresponding rates among control group members. While this is arguably a reasonable evaluation approach, the lack of finding an absolute improvement among program participants is potentially a cause for caution in interpreting the program as successful. 


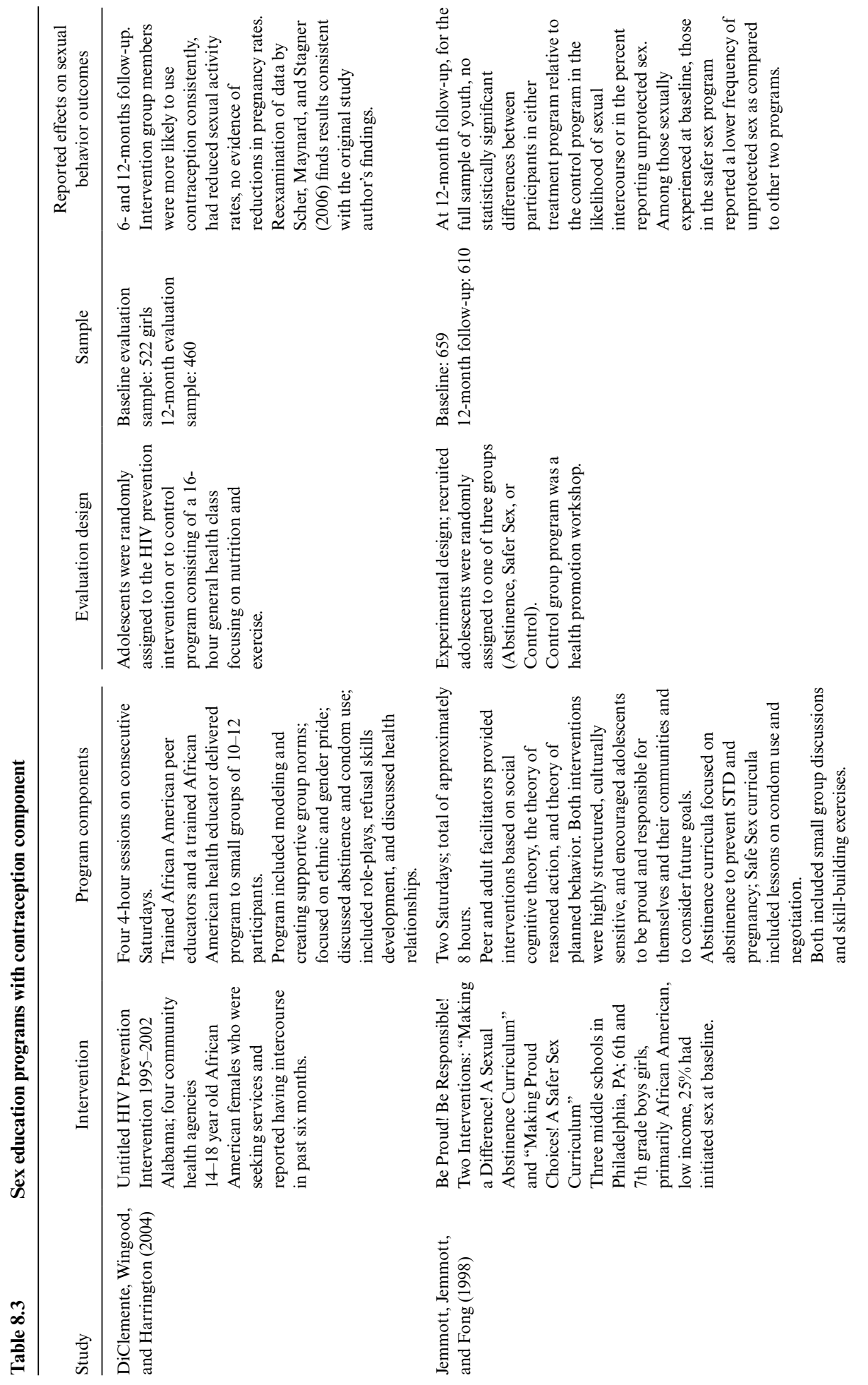




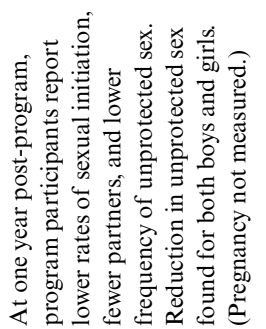

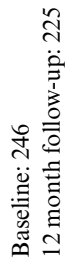

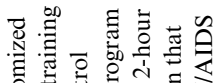

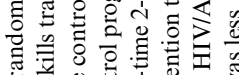

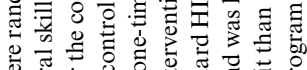

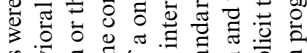

20.

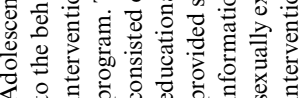

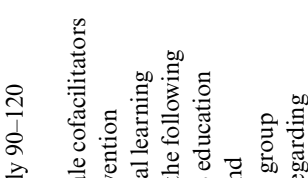

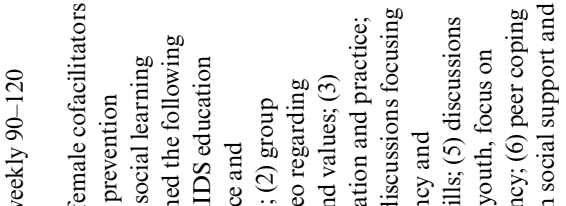

年

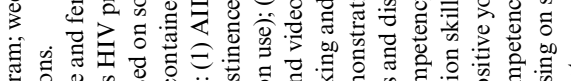

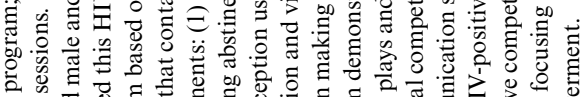

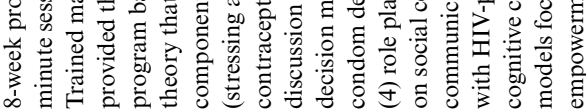

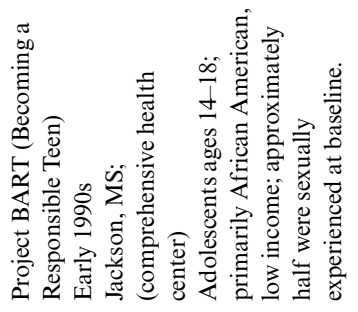

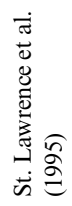

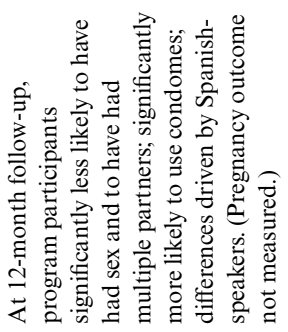

in
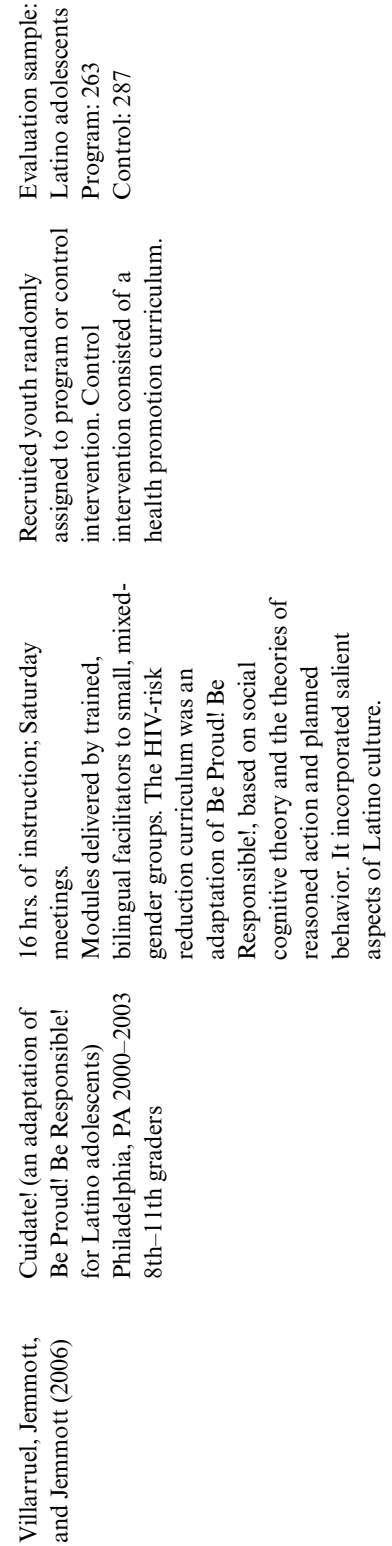
than half and implemented in a state juvenile reform center in Mississippi. In this instance of the program, the evaluation (St. Lawrence et al. 1999) did not detect any program effects on observed outcomes.

\subsubsection{Multi-Component Programs}

It is generally understood that many factors influence the process by which teenagers engage in sexual risk-taking behaviors and find themselves in the situation of being pregnant. A teenager's decision to be sexually active and the level of precaution taken against pregnancy are determined only in part - and arguably only in small part - by her knowledge about pregnancy risk and contraception. A teen's sense of self-confidence, her academic goals, her career aspirations, her relationship with her family, all of these are among the many other factors determining a teen's likelihood of engaging in risky sexual behaviors. In recognition of this, some advocates favor a more comprehensive youth development approach to teen pregnancy prevention.

The evidence from multicomponent programs serving disadvantaged youth is the most promising. Scher, Maynard, and Stagner (2006) review the evaluations of seven multicomponent programs, including the two described below. Compared to the other types of interventions reviewed, the authors view these as showing the most promising impacts, in particular for girls. However, even this small set of seven evaluated programs includes at least one program with a questionable randomized design and some that are now quite dated. The body of evidence is therefore not very solid and the reviewers caution that "there is a paucity of rigorous evaluations of such programs" (37). I highlight here two programs that have received a good amount of attention for having produced evaluations with favorable results: The Children's Aid Society-Carrera Program in New York City and the Teen Outreach Program (TOP), a service learning program that has been implemented in various sites throughout the country. Table 8.4 reports details.

The Carrera program aims to address the underlying factors associated with teenage pregnancy and childbearing, such as poverty, school failure, unemployment, and inadequate health care. It is an intensive, multiyear after-school program for high-risk high school students. The program is year-round, offered five to six days each week, and it serves teens until they complete high school. During the school year, program activities were scheduled after school each day for approximately three hours. During the summer, the program provided employment, academic assistance, and sex education for approximately three hours a day. ${ }^{9}$ The program has been evaluated

9. The cost of the program in New York City sites is reported to be approximately $\$ 4,000$ per teen per year, or an average of $\$ 16$ a day per teen. These costs included staffing, medical and dental care, stipends, and wages for teens to work in part-time or full-time jobs. The program has been funded privately through foundations and donors. In New York City, the Robin Hood Foundation provides principal support. 


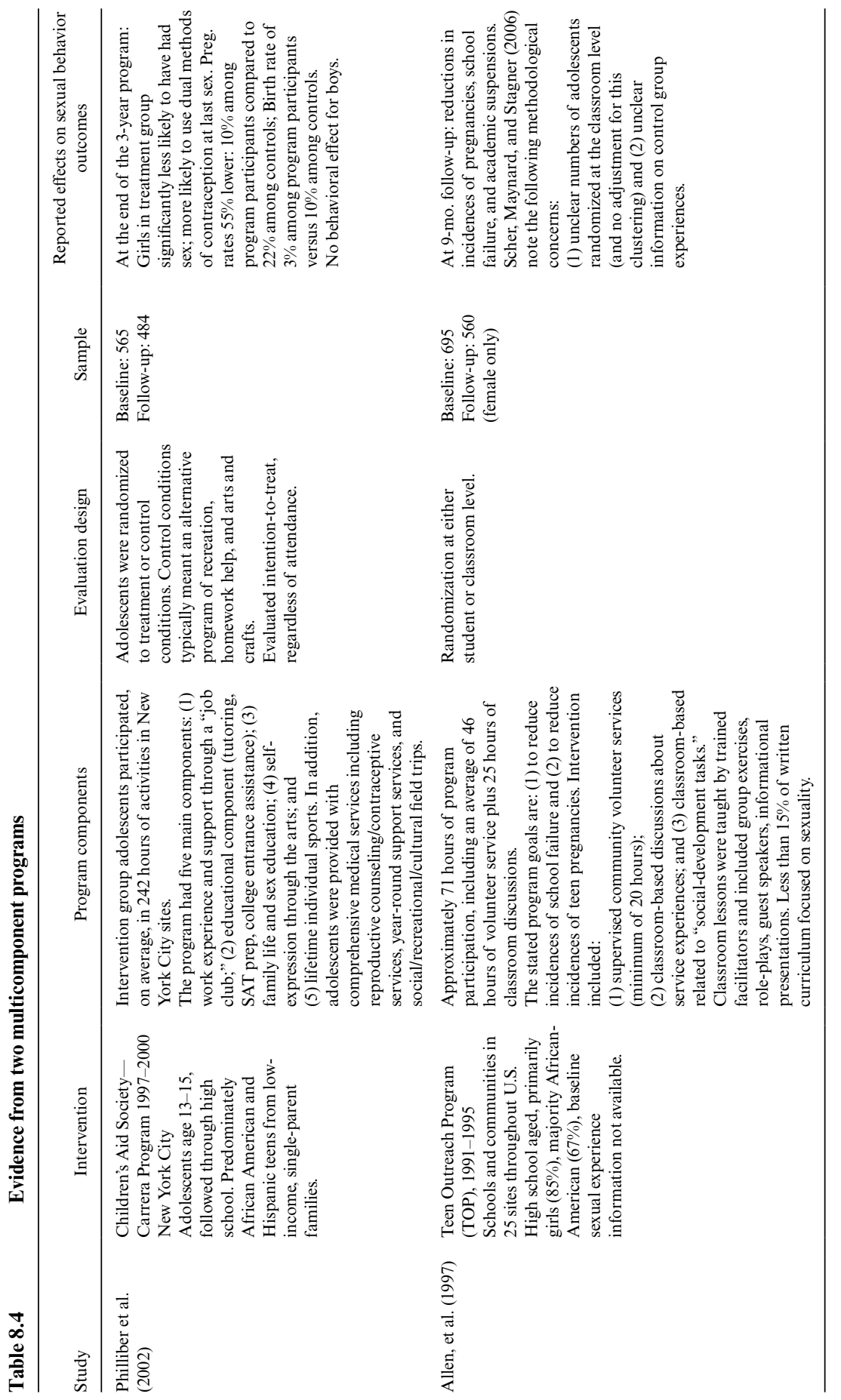


by Philliber et al. (2002) and its evaluation favorably reviewed by both Kirby (2007) and Scher, Maynard, and Stagner (2006).

The description of the program that follows is based on its operation from 1997 to 2000, the years of basis for the Philliber et al. (2002) evaluation. ${ }^{10}$ The program operated five days a week and provided services in a wide range of areas. It had five main components: (a) work experience and support through a "job club;" (b) educational component (tutoring, SAT prep, college entrance assistance); (c) family life and sex education; (d) self-expression through the arts; and (e) lifetime individual sports. In addition, adolescents were provided with comprehensive medical services including reproductive counseling and contraceptive services. The program's message was meant to unambiguously promote avoiding unprotected sex and pregnancy. The program had a full-time coordinator, a full-time community organizer, and part-time employees.

Teens were recruited from age thirteen to fifteen and encouraged to participate throughout high school. Teens spent an average of sixteen hours per month in the program during the first three years. The population served was primarily African American and/or Latino and low income. The evaluation of the New York City site involved six agencies in New York City, each randomly assigning 100 disadvantaged youths to their usual youth program or to the Carrera program. The control group experience typically involved an alternative program that included recreational activities and homework help. Both program and control youth were followed for three years; 79 percent of participants remained in the program for three full years.

Philliber et al. (2002) find no effects on the behavior of males. However, the analysis finds that female participants had significantly lower odds of being sexually active and, conditional on sexual activity, of using a condom and a hormonal method at last intercourse. There is a statistically significant reduction in the likelihood of having experienced a pregnancy. This important finding has been demonstrated in replication sites as well. ${ }^{11}$

The service-learning program Teen Outreach Program (TOP) has also been promoted as an effective teen pregnancy prevention program. This program was created in St. Louis in the 1970s and is currently found in more than four hundred schools and organizations across the country (Isaacs 2007). These programs involve both volunteer work, such as tutoring or park

10. The original program sample for this program was based in New York City. Replications took place in Baltimore, MD; Broward County, FL; Houston, TX; Portland, OR; Rochester, NY; and Seattle, WA.

11. The multicomponent Aban Aya Youth Project has also been found to have positive effects on recent sexual activity and condom use, but only for boys. This program was designed for African American youth in grades five through eight and was developed to address multiple problem behaviors such as violence, substance abuse, delinquency, and sexual activity. It is based on an Afrocentric Social Development curriculum instructed over a four-year period. The evaluation is based on self-reported behavior and does not include a measure of teen pregnancy as an outcome. See Flay et al. (2004). 
cleanup, and structured time for preparation and reflection. These programs often link the voluntary work to academic instruction in the classroom. Less than 15 percent of the written curriculum addresses issues of sexuality. Allen et al. (1997) evaluate the impact of TOP in twenty-five sites across the country in the mid-1990s. The evaluation finds a statistically significant reduction in teen pregnancy rates among female participants. However, these results should be viewed with caution, as the level of randomization did not always occur at the student level and the statistical analysis makes no adjustment for this (Scher, Maynard, and Stagner 2006). Furthermore, it is not clear what the comparison intervention constituted.

\subsubsection{Summary}

The majority of evaluations of teen pregnancy prevention programs fail to provide evidence of effectiveness. But that does not imply that such programs can never work. The state of the evidence on teen pregnancy prevention programs does not permit a general conclusion about whether one type of program unambiguously works and another unambiguously does not.

The most compelling research on representative abstinence-focused programs (Trenholm et al. 1997) finds no difference in the rates of sexual activity among students in these programs compared to sexual education courses. But, contrary to critics' claims, this empirical research also rejects the hypothesis that the abstinence-focused programs increase rates of unprotected sex. Furthermore, the evaluated programs were implemented in middle schools, and might have different impacts if implemented at the high school level, when students are more likely to be making decisions regarding sexual activity and contraception.

With regard to contraceptive-focused curriculum-based programs, it appears to be the case that in general, these programs also fail to produce noticeable changes in sexual behavior and teen pregnancy rates. But, as highlighted in the previous discussion, there are a few noteworthy curriculumbased programs that may show signs of effectiveness. Still, the effectiveness of these programs and others derived from them will depend on the particular implementation and the appropriate pairing of setting, staff, and targeted population.

There are two widely-heralded multicomponent programs that appear to have had success in bringing down rates of sexual activity and teen pregnancy. But the success of similarly designed programs will also depend crucially on the particular implementation in a particular community setting. Furthermore, the costs will vary widely. Estimates for the TOP program put the costs at around $\$ 600$ a year per student, compared to $\$ 4,000$ a year per student served by Carrera. There are two caveats to interpreting these dollar figures. On the one hand, the cost per teen pregnancy averted by these programs would be orders of magnitude higher than these per student figures, since there is nowhere near a one-to-one correspondence between the 
number of students served and the number of teen pregnancies averted. ${ }^{12}$ On the other hand, there are likely to be other benefits to the participants of these programs beyond those captured with sexual outcome measures.

\subsubsection{Simulating Pregnancy Impacts from Program Effects}

It is instructive to consider how program findings regarding delayed sexual initiation and increased use of contraception can be expected to translate into reductions in teen birth rates. Given that pregnancy is not deterministic, only some acts of unprotected sex will result in pregnancy. The rate of pregnancy resulting from unprotected sex will vary across women and couples and across the timing of the menstrual cycle in which the act occurs. Furthermore, given the imperfect nature of contraception and its use in practice, some women who use contraception, either always or sometimes, will experience a pregnancy anyway. This will depend on method used and consistency and faithfulness of use. So, even if a program has been demonstrated to increase contraceptive use among program teens, it is not entirely straightforward to predict what this will mean for rates of pregnancy. And finally, projecting impacts on birth rates from changes in predicted pregnancy rates will depend on the fraction of affected teens who would have carried the pregnancy to term and given birth.

Amato and Maynard (2007) simulate the effect of reduced sexual activity and increased contraception use on the number of teen births. Their simulations are based on population data from 2004 and information about sexual behavior and contraceptive use among teenagers from the National Survey of Family Growth (NSFG). They find that other things being equal, delaying first intercourse for one year would lower the share of twelve- to fifteenyear-olds at risk for pregnancy and birth by about 9 percentage points. The delay would reduce the number of teen births, at present rates, by about 81,000 a year, a proportional decline of 24 percent. If half of those who do not use contraception were to become consistent users of condoms, the pill, an injectable form of contraception, or an implant, the number of unintended teen births would fall another 60,000 a year, or 14 percent.

\subsection{Other Types of Interventions}

This section briefly reviews two of the major policy interventions relevant to teen pregnancy and childbearing. These include policies to expand access to affordable contraception and welfare reform. Advocates often call for increased access to contraception as a way to combat high rates of pregnancy among teens and unmarried young women. The presumption is that expanded access to (subsidized) contraception will necessarily lead to

12. Kane and Sawhill (2003) and Isaacs (2007) argue for the cost-effectiveness of such programs. 
lower rates of unprotected sex. But this need not be true. If teenagers who get pregnant are by and large not committed to avoiding pregnancy, then a policy of increased access to contraception will not have much impact. Put differently, if teens who are committed to avoiding pregnancy take the necessary measures, then those who take up the newly provided (or subsidized) services might well be those who were already using contraception, or abstaining from sex, before the policy or program change.

\subsubsection{Expanded Provision of Contraception}

What are the contraceptive practices of teens? Data from the $2002 \mathrm{Na}-$ tional Survey of Family Growth (NSFG), tabulated in Kearney and Levine (2009b), reveal that 36 percent of teens were sexually active in the past three months. Of those, 17 percent did not use contraception at their last intercourse, implying that 6 percent of teenage girls had unprotected sex in the past three months. Black and Hispanic teens are significantly less likely than their white counterparts to use contraception. Compared to a rate of 11 percent among white teenage girls, 26 percent of black teenage girls and 37 percent of Hispanic teenage girls report not using contraception at their last intercourse. The most common form of primary contraception among teens in the NSFG is the pill (44.6 percent), followed closely by condoms (40.9 percent). The trends are encouraging. In the 1995 NSFG survey data, 32 percent of teens did not use contraception at last intercourse, yielding a rate of pregnancy risk of 12 percent.

The very limited evidence from school-based contraception-availability programs is not favorable. According to Kirby (2007), the experience of such programs is that they do not appear to increase sexual activity. But unless the clinic focuses on pregnancy reduction in addition to providing contraception, they do not increase the overall use of contraceptives markedly or decrease overall rates of pregnancy or childbirth (17).

Beyond schools, policymakers in Congress are calling for expanded coverage of contraception under the public Medicaid program as a way to reduce rates of unintended pregnancy. Medicaid is now the largest source of public funding for family planning services in the country. Kearney and Levine (2009b) have evaluated the experience of states that have expanded Medicaid family planning coverage. Their analysis provides robust evidence that such expansion policies can lead to sizable reductions in teen birth rates. The results indicate that expanding eligibility to women at higher levels of income (above the traditional Medicaid eligibility level) reduced overall birth rates among teens age fifteen to seventeen by 1.2 percent and teens age eighteen to nineteen by 6.8 percent; birth rates to women age twenty to twenty-four decrease by 5.1 percent. There are no statistically significant decreases in birth rates to older women. Kearney and Levine calculate that as a result of the expansion policy, there is one birth averted for every thirtysix additional Medicaid family planning clients. This suggests program costs 
on the order of $\$ 6,800$ per averted birth, though this number cannot be calculated separately for teens.

\subsubsection{Welfare Policy}

Some scholars have argued that teen and nonmarital childbearing are facilitated and to some extent encouraged by welfare programs that enable a teen mother to financially support her own family. In response to this concern, the 1996 PRWORA legislation explicitly stated as a goal reductions in teen and nonmarital childbearing and included relevant provisions. A key provision aimed at this goal was the requirement of "family caps," which capped the monthly benefit for a family on welfare, regardless of whether the mother gave birth to an additional child. There were also requirements that teen mothers continue to live with their parents in order to qualify for benefits.

The research consensus on welfare policies is that the link between the generosity of cash welfare programs and rates of nonmarital and teen births is at best quite modest. Moffitt (1998) reviews the broad literature on welfare and concludes that the wide range of point estimates across studies suggests some (small) positive causal relationship between welfare benefits and the likelihood of female headship. Kearney (2004) and Levine (2002) find that family cap policies implemented as part of welfare reform were not effective at reducing birth rates among targeted women. Grogger and Karoly (2005) provide extensive review of welfare reform studies and conclude that "there is little evidence that welfare reform as a whole lowers childbearing" (196). ${ }^{13}$

\subsection{The Consequences of Teen Pregnancy}

It is well-documented that women who give birth as teenagers have inferior later life outcomes than women who give birth at a later age. On average they are less likely to graduate high school, they are more likely to be single mothers, they have lower wages, they have lower family income, and they are more likely to live in poverty, as are their children. These observations drive much of the common perception that teen childbearing has large adverse consequences for girls who become teen mothers. It is also these observed correlations that are behind claims about how much overall poverty has increased or decreased as a result of movements in teen childbearing rates. ${ }^{14}$

Empirical research by economists focuses on identifying the causal link

13. Abortion availability is another policy that is obviously related to teen childbearing. Phillip Levine estimates that abortion legalization in the 1970 s led to a 12 percent relative decrease in teen childbearing. However, with regard to pregnancy, expanded access to abortion could lead women and teens to take more risks with regard to getting pregnant (since abortion essentially provides a way to avoid an unwanted birth, should the woman become pregnant). Empirical examinations by economists have confirmed this prediction. For a thorough treatment of the issue, see Levine's 2004 book, Sex and Consequences.

14. For example, U.S. Congress (2004). 
between teen childbearing (or teen pregnancy) and subsequent poverty. We know that teen mothers are more likely than other mothers to live with their children in poverty, but to what extent would their subsequent poverty rates be different if they delayed childbearing into their twenties? To answer this question, we cannot merely take the lower poverty rate among women who did actually delay childbearing into their twenties. Economists talk about "selection effects" when considering such possibilities. The idea is that teenage girls who select into becoming pregnant and subsequently giving birth (as opposed to choosing abortion) are different in terms of both background characteristics and potential future outcomes than those girls who delay childbearing, either through avoiding pregnancy or choosing abortion. This is a crucial issue to resolve when trying to determine what the realized benefits would be to a program that successfully reduced teen pregnancy or teen childbearing.

To determine the costs of teen pregnancy in terms of reduced earnings and increased poverty, the key question that needs to be answered is to what extent the inferior outcomes of teen mothers are driven by the event of having given birth as a teenager, as opposed to other related factors, such as growing up in disadvantaged circumstances. For example, it is well known that girls who grow up in poverty are more likely to get pregnant and give birth as teenagers. In tabulations of data from the 2003 Panel Study of Income Dynamics (PSID), Kearney and Levine (2009a) report that among the full sample of women age twenty to thirty-five, 24 percent give birth before age twenty. But among the subsample of women age twenty to thirtyfive who were born into poverty, 49 percent give birth before age twenty. It is also understood that children who grow up in poverty are more likely to have low family income as adults. So it is almost certainly the case that at least some of the relationship between giving birth as a teen and having lower family income as an adult is due to having grown up in poverty. In other words, a girl who grows up in poverty is relatively more likely to have lower income as an adult whether or not she gives birth as a teen. This is true for other observable family characteristics such as growing up in a femaleheaded household or being born to a teen mother.

There have been a number of recent studies in which the authors have tried to carefully identify the causal effect of teenage childbearing on subsequent outcomes while holding constant family background characteristics. In one of the first studies in this line of research, Geronimus and Korenman (1992) noted that the prevailing view of teen childbearing as a cause of persistent poverty and poverty transmitted across generations was drawn from crosssectional studies comparing teen mothers to women who had their first birth at later ages. They point to a review of this early literature conducted by Hayes (1987) that linked teen childbearing to elevated high school dropout rates, rising numbers of female-headed households, and excessive rates of low birth weight and infant mortality among U.S. blacks. To isolate the effect 
of teen childbearing from the effect of family background, Geronimus and Korenman employ a "within-family" estimation approach that compares differences in subsequent socioeconomic status of sisters who experienced their first births at different ages. They analyze samples from three data sets: the National Longitudinal Survey Young Women's Sample (NLSYW), the Panel Study of Income Dynamics (PSID), and the National Longitudinal Survey Youth Sample (NLSY).

The main findings of Geronimus and Korenman (1992) are that crosssectional comparisons that do not control for detailed family background greatly overstate the costs of teen childbearing. These main findings were replicated by Hoffman, Foster, and Furstenberg (1993), but this set of authors argues in favor of larger estimated costs found among the PSID sample. In a 1993 reply piece, Geronimus and Korenman argue that even the fairly modest differences in outcomes observed in the PSID sample probably overstate the costs of teen childbearing, since sisters who give birth as teens are potentially on different (and lower) education, earnings, and income trajectories than their sisters who give birth at older ages.

This last point raises the issue that in addition to potential differences in observed and unobserved family background characteristics, girls who are more committed to achieving higher levels of educational attainment and economic success may be more committed to preventing a pregnancy from occurring during their teenage years. Such girls may also be more inclined to choose abortion if they do get pregnant. To the extent that the girls who become teen mothers expect beforehand to be on lower educational and earnings trajectories, we would have observed lower levels of educational attainment and earnings among them later in life even if they had delayed giving birth. From a research perspective, to isolate the effect of the teen birth on later outcomes, we would want to observe a sample of women who have the same potential outcomes and the same inclination to get pregnant and give birth, but by random chance, some do and some do not become teen mothers. Hotz, McElroy, and Sanders make use of a clever research strategy that arguably achieves exactly this.

Hotz, McElroy, and Sanders $(2005,1997)$ exploit the fact that some women who become pregnant as teenagers experience a miscarriage and thus do not have a birth. They carry out this empirical analysis using data from the National Longitudinal Survey of Youth (NLSY79) on women who were aged thirteen to seventeen between 1971 and 1982. Before describing the results of their analysis, it is informative to consider the descriptive statistics they report from the NLSY79. First, the data reveal that among women who become pregnant before age eighteen, there is no statistical difference in family background characteristics between those who experience a miscarriage and those who give birth. This validates their empirical approach. Second, among women who become pregnant before age eighteen, those who choose to end their pregnancy in abortion on average have family incomes 
that are 40 percent higher than those who give birth. This supports the claim that among pregnant teems, there are important selection effects driving the decision to become a teen mother.

The consequences of teen childbearing measured by Hotz, McElroy, and Sanders (2005) can be interpreted as the effect of not delaying childbearing for women who become pregnant as teenagers. Importantly, this is the group that is of interest from a policy or program point of view since these are the girls who are targeted by teen pregnancy prevention programs. The authors begin by replicating previous findings of adverse consequences, using straightforward regression techniques that compare outcomes for teen mothers and those who delay childbearing. But when they employ their miscarriages experiment, and thereby avoid confounding selection effects, none of the differences are statistically significant, and some are even reversed in sign, suggesting potentially beneficial effects of teen childbearing for these women. A recent reexamination of this data and approach by Saul Hoffman (2008) finds that the estimated impacts of a teen birth are more negative for teen mothers who had births in the early 1980s relative to 1970 s. Looking separately at these two groups of teen mothers suggests that the consequences of teen motherhood may be more negative for more recent cohorts of women.

A recent study by Ashcraft and Lang (2006) builds directly on the Hotz, McElroy, and Sanders study. Their analysis is based on data from the 1995 wave of the National Survey of Family Growth (NSFG), which they claim is better suited for measuring pregnancy outcomes than the NLSY. They argue that the miscarriage experiment approach taken by Hotz and colleagues provides an unbiased estimate of the effects of teen childbearing under two conditions: (a) miscarriages are (conditionally) random across pregnant teens and (b) all miscarriages occur before teenagers can obtain abortions. But as Ashcraft and Lang argue, some girls choose to abort their pregnancies before a potential miscarriage (spontaneous abortion) occurs. They confirm in their data that pregnant teens who obtain an abortion are more likely to come from advantaged backgrounds. Thus, the sample of teens who delay childbearing due to a miscarriage are more likely to be teens who would have chosen to give birth, meaning that they might have had less to lose in terms of educational attainment or earnings from teen childbearing then those who did not. Ashcraft and Lang replicate the Hotz, McElroy, and Sanders approach and confirm that when the analysis sample is limited to pregnant teens who either give birth or miscarry (by excluding girls who obtain an abortion), the estimated effects of teen childbearing move from slightly positive to slightly negative.

Ashcraft and Lang (2006) convincingly demonstrate that the two approaches provide upper and lower bounds on the consequences of teen childbearing. They combine the bounds from the two approaches with some additional information about abortion and miscarriage likelihoods to pro- 
duce statistically consistent estimates of the effect of teen childbearing on those teenagers who would choose to give birth (as opposed to have an abortion). They report the following estimated effects for the sample of women who were at least twenty years old at the time of the survey and who had their first pregnancy before age eighteen: (a) the likelihood of being currently married is reduced by about 3 percentage points; (b) total number of children is increased on average by 0.8 ; (c) completed education is reduced by about 0.15 years; (d) the probability of working is reduced by about 5 percentage points, earnings conditional on working are not affected; (e) family income is unaffected. The conclusion of their work is that while teen childbearing might not be as benign as suggested by the results of Hotz, McElroy, and Sanders (2005), any adverse consequences on socioeconomic outcomes that exist are quite small in magnitude.

\subsubsection{Reconciling the Research with the Perception}

The collective results of these careful studies call into question the view that postponing childbearing will substantially improve the socioeconomic attainment of teen mothers. And if there are not observable improvements in outcomes for the teen mothers themselves, there are not likely to be observable improvements in outcomes for the children of these mothers. How should one reconcile the finding that teen childbearing is not very costly for teen mothers (and potentially their children) with the common perception of substantial consequences? I offer a few observations on this point. The first is the interpretation of the results offered by Hotz, McElroy, and Sanders (2005). The authors note that women who begin motherhood as teens come from less advantaged backgrounds, are less likely to be successful in school, and as such, are less likely to end up in occupations that require higher education compared with women who postpone childbearing. This would explain the absence of adverse, or very large adverse, effects on subsequent work probabilities, earnings, and family income.

A second important observation is that the estimated effects are for teens who choose to carry their pregnancy to term. If abortion were not available as an option, it is likely that the observed effects of teen childbearing would be different because women who would prefer to avoid teen childbearingpresumably because they expect it to have negative consequences-would not have that choice. Tabulations from the 1995 NSFG presented in Ashcraft and Lang (2006) reveal that among first pregnancies to teens under age eighteen, 10 percent are resolved in a miscarriage, 25 percent end in abortion, and 65 percent result in a live birth. ${ }^{15}$ In terms of background characteristics, pregnant teens who obtain an abortion are more likely to come from families with higher levels of parental education and are more likely to be

15. As a side note, if reducing abortion were the goal, as opposed to reducing poverty, then teen pregnancy prevention could very well be an effective investment. 
white. Among the pregnant teens who give birth, 41 percent receive a high school diploma, as compared to 73 percent among those who obtain abortions. From these unadjusted comparisons, we might suspect that part of that difference reflects the negative consequence of giving birth. But among those who miscarry, only 45 percent earn a high school diploma. These numbers reveal that pregnant teens who delay childbearing due to nature (miscarriage) rather than their own choice (abortion) do not complete high school at noticeably higher rates. This fact strongly suggests that teenage girls who intend to achieve higher levels of education, and presumably labor market career outcomes, are more likely to avoid teen childbearing, even if they become pregnant.

Third, we need to think about what avoiding teen childbearing or teen pregnancy means in terms of subsequent childbearing. Among the sample of pregnant teens in Ashcraft and Lang's 1995 NSFG sample, the average age of next pregnancy is 19.6. That suggests that even if programs are successful at getting teens to avoid becoming pregnant in any given year, there is a fairly sizable chance that they will initiate childbearing before their late twenties. And it seems reasonable to speculate that the chances of them waiting until they are in a stable marriage are even smaller. This is potentially what is needed to observe improvements not just for the teen mothers themselves, but also for their children.

It is potentially the case that a longer delay of childbearing initiation, to older ages or a more stable economic or relationship situation, is what is needed in order to see a real positive change in the life course of these teen moms, and perhaps in the lives of their children. Importantly, this might be why the Hotz, McElroy, and Sanders and Ashcraft and Lang papers fail to find large consequences of teen childbearing. The miscarriage "intervention" studied by those papers is only about delaying childbearing past teenage years. If a teen pregnancy prevention program affects more than just the fact of a pregnancy in a given year, say by achieving a longer delay in childbearing initiation or the formation of life-improving skills and aspirations, then larger, more positive effects on subsequent life outcomes could potentially be achieved.

This final point, related to the previous observation, is that perhaps it is not teen childbearing in particular that is consequential, but nonmarital childbearing. In other words, even if these teen mothers were to avoid childbearing until they were in their twenties, if they were still to become single mothers, their rates of poverty would be unaffected. It is well-known that single mothers have the highest rates of poverty. According to 2006 Census figures, 5.7 percent of people living in married couple families live below the federal poverty threshold, as compared to 30.5 percent of people living in female-headed households. ${ }^{16}$ Amato and Maynard (2007) argue that school 
and community programs to help prevent nonmarital births would reduce poverty.

Furthermore, while this piece has focused on the outcomes of teen mothers themselves, much of the public concern about teen pregnancy is driven by concern for the children of these teen mothers. Though there is a lack of compelling evidence suggesting that delaying teen childbearing would noticeably improve outcomes for children, there is overwhelming evidence that children raised in a family with two biological parents fare much better in terms of economic and cognitive outcomes than children raised in singlemother households.

\subsection{Final Discussion}

The research reviewed in this chapter suggests that the socioeconomic consequences of teen childbearing for teen mothers are at worst only modestly adverse. The most methodologically compelling studies demonstrate that the lower rates of high school completion, lower rates of marriage, lower family income, and higher rates of poverty observed among women who were teen mothers reflect selection effects as opposed to the consequences of teen childbearing itself. It appears to be the case that girls who become pregnant and give birth tend to be headed for lower levels of educational attainment and family income even before the event of the teen birth. A pessimistic reading of these results might lead one to conclude that teen pregnancy prevention programs are therefore not effective investments if the goal is to reduce poverty.

A more ambitious take-away is that the previous discussion makes the case that in order to reduce poverty and improve adult outcomes, programs designed to reduce teen pregnancy need to focus on a much broader set of outcomes. Successful programs would steer teenage girls away from whatever sense of disadvantage it is that is leading them to become teen mothers. This could mean equipping these girls with skills that would facilitate educational and labor market success. It could mean helping reshape their life vision and ambitions. In their ethnographic study of single mothers in a poor urban setting, Edin and Kafalas (2006) observe that many of the women in their sample became mothers because they saw it as something positive they could achieve. They observe that "the daily stresses of an impoverished adolescence ... breed a deep sense of need for something positive to "look to"' (205). If teen childbearing is not costly for teen mothers because these girls were not aiming for education or labor market success, then arguably the best investment would be to successfully change their goals and aspirations and put them on the path to a better life. And in fact, as the review of the aforementioned program interventions suggests, this is just the kind of program that is showing signs of success in reducing teen pregnancy. 


\section{References}

Allen, J. P., S. Philliber, S. Herrling, and G. P. Kupermine. 1997. Preventing teen pregnancy and academic failure: Experimental evaluation of a developmentally based approach. Child Development 64 (4): 729-42.

Amato, P. R., and R. A. Maynard. 2007. Decreasing nonmarital births and strengthening marriage to reduce poverty. Future of Children 17 (2): 117-41.

Ashcraft, A., and K. Lang. 2006. The consequences of teenage childbearing. NBER Working Paper no. 12485. Cambridge, MA: National Bureau of Economic Research, August.

Brooks-Gunn, J., and F. F. Furstenberg, Jr. 1989. Adolescent sexual behavior. American Psychologist 44 (2): 249-57.

Brooks-Gunn, J., and R. Paikoff. 1997. Sexuality and developmental transitions during adolescence. In Health risks and developmental transitions during adolescence, ed. J. Schulenberg, J. L. Maggs, and K. Hurrelmann, Cambridge: Cambridge University Press.

DiClemente, R. J., G. M. Wingood, and K. F. Harrington. 2004. Efficacy of an HIV prevention intervention for African American adolescent girls. Journal of the American Medical Association 292 (2): 171-79.

Edin, K., and M. Kefalas. 2005. Promises I can keep: Why poor women put motherhood before marriage. Berkeley, CA: University of California Press.

Flay, B. R., S. Graumlich, E. Segawa, J. L. Burns, and M. Y. Holliday. 2004. Effects of 2 prevention programs on high-risk behaviors among African American youth: A randomized trial. Pediatric Adolescent Medicine 158 (April): 377-84.

Geronimus, A. T., and S. Korenman. 1992. The socioeconomic consequences of teen childbearing reconsidered. Quarterly Journal of Economics 107 (4): 1187-214.

. 1993. The socioeconomic costs of teen childbearing: Evidence and interpretation. Demography 30 (2): 281-90.

Geronimus, A. T., S. Korenman, and M. M. Hillemeier. 1994. Does young maternal age affect child development? Evidence from cousin comparisons in the United States. Population and Development Review 20 (3): 585-609.

Grogger, J., and L. A. Karoly. 2005. Welfare reform: Effects of a decade of change. Cambridge, MA: Harvard University Press.

Guttmacher Institute. 2006. U.S. teenage pregnancy statistics: National and State trends and trends by race and ethnicity. New York: Guttmacher Institute.

Hayes, C. D. 1987. Adolescent pregnancy and childbearing: An emerging research focus. In Risking the future, volume 2, ed. S. L. Hofferth and C. D. Hayes, 1-6. Washington, DC: National Academy Press.

Hoffman, S. D. 2008. Updating the teen miscarriage experiment: Are the effects of a teen birth becoming more negative? Working Paper no. 08-08. University of Delaware, Department of Economics.

Hoffman, S., M. Foster, and F. F. Furstenberg, Jr. 1993. Reevaluating the costs of teen childbearing. Demography 30:1-13.

Hotz, V. J., S. W. McElroy, and S. Sanders. 2005. Teenage childbearing and its life cycle consequences: Exploiting a natural experiment. Journal of Human Resources 40 (3): 683-715.

Hotz, V. J., C. Mullin, and S. Sanders. 1997. Bounding causal effect using data from a contaminated natural experiment: Analyzing the effects of teenage childbearing. Review of Economic Studies 64 (4): 575-603.

Isaacs, J. B. 2007. Cost-effective investments in children. Budgeting for National Priorities Paper. Washington, DC: Brookings Institution, January.

Jemmott, J., III, L. Jemmott, and G. Fong. 1992. Reductions in HIV risk-associated 
sexual behaviors among black male adolescents: Effects of an AIDS prevention intervention. American Journal of Public Health 82 (3): 372-77.

1998. Abstinence and safer sex HIV risk-reduction interventions for African American adolescents: A randomized controlled trial. Journal of the American Medical Association 279 (19): 1529-36.

Jemmott, J., III, L. Jemmott, G. Fong, and K. McCaffree. 1999. Reducing HIV riskassociated sexual behaviors among African American adolescents: Testing the generality of intervention effects. American Journal of Community Psychology 27 (2): 161-87.

Jorgensen, S. R., V. Potts, and B. Camp. 1993. Project taking charge: Six-month follow-up of a pregnancy prevention program for early adolescents. Family Relations 42 (4): 401-06.

Kane, A., and I. Sawhill. 2003. Preventing early childbearing. In One percent for the kids, ed. I. Sawhill, 56-75. Washington, DC: Brookings Institution.

Kearney, M. S. 2004. Is there an effect of incremental welfare benefits on fertility behavior? A look at the family cap. Journal of Human Resources 39 (2): 295-325.

Kearney, M. S., and P. B. Levine. 2009a. Socioeconomic disadvantage and early childbearing. In An economic perspective on the problems of disadvantaged youth, ed. J. Gruber, 181-209. Chicago: University of Chicago Press.

2009b. Subsidized contraception, fertility, and sexual behavior. Review of Economics and Statistics 91(1): 137-51.

Kirby, D. 1997. No easy answers: Research findings on programs to reduce teen pregnancy. Washington, DC: National Campaign to Prevent Teen Pregnancy.

_. 2001. Emerging answers: Research findings on programs to reduce teen pregnancy. Washington, DC: National Campaign to Prevent Teen Pregnancy.

- 2007. Emerging answers 2007: Research findings on programs to reduce teen pregnancy and sexually transmitted disease. Washington, DC: National Campaign to Prevent Teen Pregnancy.

Kirby, D., M. Korpi, C. Adivi, and J. Weissman. 1997. An impact evaluation of Project SNAPP: An AIDS and pregnancy prevention middle school program. AIDS Education and Prevention 9 (A): 44-61.

Kirby, D., M. Korpi, R. Barth, and H. Cagampang. 1995. Evaluation of education now and babies later (ENABL): Final report. Berkeley, CA: University of California, School of Social Welfare.

Levine, P. B. 2002. The impact of social policy and economic activity throughout the fertility decision tree. NBER Working Paper no. 9021. Cambridge, MA: National Bureau of Economic Research, June.

2004. Sex and consequences: Abortion, public policy, and the economics of fertility. Princeton, NJ: Princeton University Press.

Maynard, R. A., ed. 1997. Kids having kids: Economic costs and social consequences of teen pregnancy. Washington, DC: The Urban Institute Press.

Moffitt, R. 1998. The effect of welfare on marriage and fertility: What do we know and what do we need to know? In Welfare, the family, and reproductive behavior, ed. R. Moffitt, 50-97. Washington, DC: National Research Council, National Academy of Sciences Press.

Philliber, S., J. W. Kaye, S. Herrling, and E. West. 2002. Preventing pregnancy and improving health care access among teenagers: An evaluation of the Children's Aid Society-Carrera Program. Perspectives on Sexual and Reproductive Health 34 (5): 244-51.

Ribar, D.C. 1994. Teenage fertility and high school completion. Review of Economics and Statistics 76 (3): 413-24.

Santelli, J. S., J. Abma, S. Ventura, L. Lindberg, B. Morrow, J. Anderson, S. Lyss, 
and B. Hamilton. 2004. Can changes in sexual behaviors among high school students explain the decline in teen pregnancy rates in the 1990s? Journal of Adolescent Health 35 (2): 89-90.

Scher, L., R. Maynard, and M. Stagner. 2006. Interventions to reduce pregnancyrelated outcomes among teenagers. Social Welfare Review Groups: Campbell Collaboration. Available at: http://www.campbellcollaboration.org/doc-pdf/ teenpregreviewdec2006.pdf.

Schinke, S. P., B. J. Blythe, L. D. Gilchrist, and G. A. Burt. 1981. Primary prevention of adolescent pregnancy. Social Work With Groups 4 (1-2): 121-35.

St. Lawrence, J., R. Crosby, L. Belcher, N. Yazdani, and T. Brasfield. 1999. Sexual risk reduction and anger management interventions for incarcerated male adolescents: A randomized controlled trial of two interventions. Journal of Sex Education and Therapy 24 (1-2): 9-17.

St. Lawrence, J., R. Crosby, T. Brasfield, and R. O'Bannon, III. 2002. Reducing STD and HIV risk behavior of substance-dependent adolescents: A randomized controlled trial. Journal of Consulting and Clinical Psychology 70 (4): 1010-21.

St. Lawrence, J., K. Jefferson, E. Alleyne, T. Brasfield, R. O'Bannon, and A. Shirley. 1995. Cognitive-behavioral intervention to reduce African American adolescents' risk for HIV infection. Journal of Consulting and Clinical Psychology 63 (2): 221-37.

Thomas, B. H., A. Mitchell, M. C. Devlin, C. Goldsmith, J. Singer, and D. Watters. 1992. Small group sex education at school: The McMaster Teen Program. In Preventing adolescent pregnancy: Model programs and evaluations, ed. B. C. Miller, J. C. Card, R. L. Paikoff, and J. L. Peterson, 28-52. Newbury Park, CA: Sage Publications, Inc.

Thomas, M. H. 2000. Abstinence-based programs for prevention of adolescent pregnancies. Journal of Adolescent Health 26 (1): 5-17.

Trenholm, C., B. Devaney, K. Fortson, L. Quay, J. Wheeler, and M. Clark. 2007. Impacts of four Title V, Section 510 abstinence education programs: Final report. Mathematica Policy Research Inc., April.

U.S. Census Bureau. 2007. Current population survey, 2007 annual social and economic supplement. Washington, DC: U.S. Census Bureau.

U.S. Congress, Ways and Means Committee-Democrats. 2004. Steep decline in teen birth rate: Significantly responsible for reducing child poverty and single-parent families. Committee Issue Brief, Washington, DC.

U.S. Department of Health and Human Services. 2005. National Center for Health Statistics, National Vital Statistics Report 55 (1). Available at: www.cdc.gov/ nchs/data/nvsr/nvsr55_01.pdf.

Villarruel, A. M., J. B. Jemmott, III, and L. S. Jemmott. 2006. A randomized controlled trial testing an HIV prevention intervention for Latino youth. Pediatric Adolescent Medicine 160 (August): 772-7. 